\title{
Implementing a CEAB Engineering Graduate Attributes Based Co-op Work Term Curriculum
}

This paper discusses the process of developing a curriculum for engineering students to use during their co-op work terms that is based on the Engineering Graduate Attributes of the Canadian Engineering Accreditation Board (CEAB).

The goal of the new curriculum is to enable students to demonstrate their professional growth with respect to four selected $\mathrm{CEAB}$ attributes. It is based on the creation of a learning portfolio that demonstrates the students learning accomplishments through a combination of narrative and evidence. The evidence will be provided through a series of assignments and the narrative will be based on a series of reflective questions.

The intention is for the curriculum to not only allow students to track and articulate the development of the selected attributes but to also enable them to acquire a deeper understanding of how their work place experiences contributed to their professional growth with respect to the attributes.

The paper includes a summary of the pilot study of the initial curriculum design, a description of the current iteration of the curriculum, an outline of the implementation strategy and a short discussion of several operational challenges associated with implementation.

\section{Initial Work Term Curriculum Pilot Study}

The Faculty of Engineering has been examining ways to enhance the educational value of cooperative education for several years. To that end, a revised work term curriculum was designed and implemented in 2008/09 as a pilot study in an attempt to understand its educational impact.

This curriculum was based on students completing a series of cumulatively linked learning activities that were tracked and analyzed in a professional practice portfolio. It was designed to have authentic and meaningful assignments for students that were embedded into the work experience and at the same time balanced the student's academic work load with the work term work load. It was designed to emphasize the connections between the work experience and

a) the Engineer-in-Training (EIT) program;

b) the development writing skills;

c) the $\mathrm{CEAB}$ engineering graduate attributes, and;

d) the importance of self-directed learning.

The curriculum learning activities included:

1. Developing, tracking and reporting on a specified number of learning goals

2. Keeping a daily work log book

3. Writing monthly analyses of significant learning events

4. Completing the EIT Monthly Experience Records

5. Completing a self-assessment of the engineering graduate attributes

6. Having a performance appraisal completed by the work supervisor 
7. Writing a capstone report on the learning that occurred

8. Participating in a post-work term debriefing session

Specifically, we wanted to study:

a) student perceptions of the educational value of revised curriculum versus the original curriculum

b) work term supervisor perceptions of the revised curriculum

c) resources required to deliver the revised curriculum

The pilot study was conducted during the Fall 2008 and Winter/Summer 2009 work terms. All current co-op students were invited to apply to participate in the pilot. Students were offered a refund of their $\$ 300$ Co-op fee for successful participation and completion in the pilot program. The applications were vetted by the Co-op Office to ensure an adequate mix of disciplines and work term levels.

For the purposes of the pilot study, the curriculum assignments were developed for delivery online via Blackboard Learning System (BLS). Two instructors were hired to grade the goal setting, monthly memos and capstone report writing assignments. The monthly experience records were graded by faculty members. Co-op Office staff graded the debriefing sessions, prework term module and graduate attributes self-assessments.

Although the size of the pilot group was small i.e. 22 pilot group students and their employers and 259 non-pilot students, the survey results indicate that the revised curriculum not only met the same learning outcomes as the current curriculum, it had several advantages including improved writing skills, improved ability to articulate learning, more awareness of the connection between work terms and the EIT program, and it took slightly less time for the students to complete than the original curriculum. Please note that the pilot survey results are not included this paper but can be made available upon request.

While the pilot results strongly indicated the value of revising the work term curriculum we realized that the engineering graduate attributes should serve as the focal point of the curriculum rather than as an adjunct to it. However, given the wide range of work term environments and the need to simply the curriculum delivery, it was decided that trying to incorporate 12 attributes into the curriculum would be less effective than focussing on a smaller subset of them.

\section{Current Iteration of the Work Term Curriculum}

Consequently the curriculum was shifted to focus on the graduate attributes. The learning outcomes for the first work term are for students to be able to:

A. Demonstrate their progress with developing four graduate attributes

B. Identify and describe the aspects of their work term that contributed to, and detracted from, their progress with the selected attributes

C. Summarize how the attributes connect with:

1. the EIT program

2. logbook keeping

3. performance feedback 


\section{4. career planning}

To achieve these goals, students create a 'learning portfolio' during each work term that demonstrates their learning accomplishments through a combination of narrative and evidence. Students complete the assignments in section one, plus one of the two other portfolio components.

Portfolio Components:

1. Assignments:

i. Graduate Attributes Self-Assessment

ii. Work Term Goal Setting and Action Plan Exercise

iii. Monthly EIT records

iv. Daily Logbook

v. Supervisors Performance Appraisal

vi. Career Planning Exercise

2. Narrative: Students will answer a series of questions related to each learning outcome.

Or,

3. Technical Report combined with an annotated work sample demonstrating significant advancement with one attribute, can be in lieu of the narrative questions for one work term.

Each learning outcome has its own objectives and activities.

Learning Outcome A: Make demonstrable progress with developing the following graduate attributes

\section{Objectives:}

- devise and apply a plan for developing attributes on the work term

- document attribute development during the work term

\section{Activities:}

1. Complete or update the attribute your self-assessment inventory

2. For each attribute, set one learning goal and create an action plan

3. Discuss your learning goals and the related graduate attributes with your work term supervisor

4. Document your attribute development in your logbook and EIT records when applicable

5. Discuss your learning goals and progress with developing your attributes during the site visit

6. Get feedback on your attributes development from supervisor via the performance appraisal

7. Update your attribute self-assessment at the end of the work term

8. Answer the following questions as part of the narrative in your portfolio:

1. Describe the extent to which you achieved each learning goal. 
2. Describe the extent to which you made progress with each attribute over the work term.

3. Did the learning goals help you to develop the related attribute? If yes, explain how, if no explain why not.

4. Provide examples of other work related activities that helped you develop your attributes?

\section{Curriculum Implementation and Timelines}

This version of the curriculum has several more design steps to complete before we will be ready to seek the appropriate institutional approvals. These include; determining the optimal method for assessing the assignments, developing rubrics for each assignment, and developing the tools and exercises that students will use. Once these stages of the design are complete it will allow us to determine the resources that will be required for ongoing delivery of the curriculum.

Additionally, the design process for the work term curriculum is tied into the Faculty level Outcomes Based Curriculum Design project which will allow us to identify the four attributes that we want to focus student attention on during the work terms.

Once the above steps have been completed the implementation schedule may look like the following:

\begin{tabular}{|l|l|}
\hline Activity & Timeline \\
\hline $\begin{array}{l}\text { Develop work term curriculum content for e-learning environment } \\
\text { including a module to solicit feedback from students }\end{array}$ & Months 1-3 \\
\hline Determine schedule of due dates for assignments & Month 1 \\
\hline $\begin{array}{l}\text { Add an introduction of the curriculum to the existing coop orientation } \\
\text { course }\end{array}$ & Month 1 \\
\hline $\begin{array}{l}\text { Determine which elements of the curriculum should be integrated with } \\
\text { the coop database (i.e. can we create auto alerts when assignment dues } \\
\text { dates are looming?) }\end{array}$ & Month 1-2 \\
\hline Update existing documentation and web pages with revised curriculum & Month 2 \\
\hline Get employer buy-in (see next section for details) & Month 1-3 \\
\hline Redesign site visit protocols to align with the new curriculum & Month 3 \\
\hline Redesign performance appraisal form to align with new curriculum & Month 3 \\
\hline Launch work term course on BLS & Month 4 \\
\hline $\begin{array}{l}\text { Monitor student activity, provide support and feedback during the work } \\
\text { term }\end{array}$ & Months 5-9 \\
\hline Assess assignments during the work term & Months 5-9 \\
\hline Conduct site visits and get feedback & Month 6/7 \\
\hline Tally assignment grades and assign final grade & Month 10 \\
\hline Upload grades into student information system & Month 10 \\
\hline Review student feedback on the course to identify improvements & Month 10 \\
\hline Implement improvements & Month 12 \\
\hline
\end{tabular}

Operational Challenges 
Implementing a complex curriculum across 11 different programs that accrue over 600 placements per year, with 400 employers across the country will present some significant operational challenges. The issues we are reviewing at this time are:

1. Creating an optimal method for assessing the assignments

2. Acquiring the resources for ongoing delivery

3. Getting employer buy-in

Assessment and feedback on the assignments will be critical to the student's development. It is assumed that finding the optimal way to give useful feedback will take trial and error. Research of best practices for assessing experiential learning is underway; however there is an opportunity to access several sources of funding to conduct a distinctive research project on this topic.

The assessment methods we choose will have the most significant impact on the cost of delivering the curriculum. This means that we cannot make any projections on the economic viability of the curriculum until we have identified at least a preliminary method to use. It is anticipated that the majority of the expenses will have to be offset by increased coop fees and fortunately the current fee has been on the low end of the national scale for a long time. But this means that we will have to be able to clearly demonstrate the added value that students will receive by engaging in this type of learning experience. The costs for the design portion of the project have been covered by the Coop Office.

The last operational issue under consideration at this time is establishing employer buy-in. We know from our pilot, and from feedback we solicited prior to conducting the pilot, that most employers are amenable to students completing assignments that enhance professional development. We also know, anecdotally, that employers are enthusiastic about the concept of the graduate attributes. But the pilot study revealed that there are work situations that will be problematic for example there is the issue of confidentiality and the issue of the requirement for organizational signoff of all assignments. Both of these situations will have to be managed.

With respect to employer buy-in our goals are to create a curriculum that is student directed, adaptable to any work environment, and provides a framework for supervisors to aid their student's professional development. To accomplish that we plan to:

a) Conduct focus groups and telephone interviews with employers to obtain their feedback

b) Process the feedback and incorporate it into the curriculum design

c) Follow up with employers to update them on the revisions

d) Develop hard copy and web materials to promote the new curriculum

e) Conduct an email campaign to educate employers on the new curriculum

f) Have coordinators introduce the curriculum at the earliest possible stage of the employer development cycle

g) Have coordinators solicit feedback during the work site visit

h) Follow up with employers who are late submitting the performance appraisals

i) Solicit feedback from employers on the curriculum following the work term

In conclusion, developing a viable curriculum that significantly enhances students' ability to develop graduate attributes during work terms is a complex and challenging process. It is work 
that should be shared and discussed amongst all engineering coop programs so that we can leverage the power of our collective synergy to improve the quality of work terms across the country. 